\title{
Losartan Potassium Loaded Bioadhesive Micro-Matrix System: An Investigation on Effects of Hydrophilic Polymeric Blend on Drug Release
}

\section{Madhusmruti Khandai', Santanu Chakraborty2*and Ashoke Kumar Ghosh ${ }^{3}$}

${ }^{1}$ P.G. Department of Pharmaceutics, Royal College of Pharmacy and Health Sciences, Berhampur, Odisha, India

${ }^{2}$ Formulation Development Research Unit, Department of Pharmaceutics, Dr. B.C.Roy College of Pharmacy and AHS, Durgapur-06, West Bengal, India

${ }^{3}$ School of Pharmaceutical Sciences, IFTM University, Moradabad-244 102, Uttar Pradesh, India

\begin{abstract}
Objective: The objective of this present investigation was to develop micro matrix sustained release dosage form of losartan potassium using combination of hydrophilic swellable polymers (sodium alginate and guar gum) to obtain a desired sustained drug release.

Methods: Ionic gelation technique was used to fabricate all the formulation due to its simple, cost effective and non consumption of organic solvents nature. The effect of polymeric ratio and its blend on dependent parameters (i.e. various physicochemical parameters and in vitro drug release) were studied to optimize the concentration of polymeric blend required for $12 \mathrm{~h}$. sustain release. In vitro wash off test and stability study was performed to investigate the mucoadhesion nature and shelf life of the optimized formulation.

Results: Concentration of guar gum was found to be the main influential factor for $12 \mathrm{~h}$ sustained drug release. The mucoadhesion property was strongly dependent on the $\mathrm{pH}$ of the medium and the polymeric concentration in the formulations. In vitro drug release study proposed a combined drug release mechanism, partially involving the spheres erosion and drug diffusion from the micro matrix system. SEM study and stability analysis revealed that optimized microspheres were almost spherical in shape with a shelf life of about 2.56 years. These prospective results also revealed that sodium alginate alone could not efficiently control the drug release, while combination with guar gum could retard the release of losartan potassium for desire period.
\end{abstract}

Conclusion: So it is concluded that combination of hydrophilic swellable polymers is an essential polymeric blend to deliver losartan potassium for prolong period and improve patient compliance.

Keywords: Micro-matrix; Losartan potassium; Bioadhesion; SEM; Guar gum; Sustain release

\section{Introduction}

Losartan potassium (LP) is a (imidazole derivative, potassium salt) potent, non-peptide, highly specific angiotensin II (type 1) receptor antagonist used in the management of hypertension [1]. LP helps to create arteriolar and venous dilation and block aldosterone secretion, thus lowering the blood pressure as well as decreasing salt and water retention. It is readily absorbed from the gastrointestinal tract with oral bioavailability of about $33 \%$ and plasma elimination half life is 1.5 to $2.5 \mathrm{~h} \mathrm{[2]}$. The short biological half-life and low bioavailability make losartan potassium an ideal candidate for sustain release dosage form for a period of $12 \mathrm{~h}$ to allow protracted antihypertensive effects by maintaining the plasma concentrations of the drug well above the therapeutic concentration [3].

In this respect, a number of researches had been carried out by preparing sustained or controlled release tablets of losartan potassium. But single unit sustained or controlled release tablets sometime dangerous if they cause dose dumping. This problems can only be overcome by formulating multiunit microspheres where the drug get distributed in numbers of spheres which are distributed throughout the GIT and release the drug in a sustain manner for prolong period of time [4].

From past few years, considerable attention has been focused on natural and semi-synthetic hydrophilic gums or polymers (i.e. guar gum, sodium alginate, xanthan gum, hydroxypropyl methylcellulose etc.) in designing oral sustained drug delivery systems due to their flexibility to obtain a desirable drug release profile, cost-effectiveness, biocompatible and biodegradable properties. However, with a single hydrophilic swellable polymer the desire drug release is not always obtained and it has been recommended that combinations of these polymers are more likely to provide the desired drug release [5].

Losartan potassium loaded sodium alginate microspheric drug delivery system was already reported by Khandai et al. [6] but the drug release achieved was significantly faster than the desire drug release. Hence, in the present study, combination of hydrophilic swellable polymers (i.e. sodium alginate and guar gum) was chosen to obtain a desired sustained drug release from microspheric device of losartan potassium.

Alginate, a natural anionic polysaccharide found in cell walls of marine brown algae is a linear copolymer with homopolymeric blocks of (1-4)-linked b- D-mannuronate (M) and its C-5 epimer a-L-guluronate $(\mathrm{G})$ residues, respectively, covalently linked together in different sequences or blocks. Alginate shows a unique property of

*Corresponding author: Santanu Chakraborty, Formulation Development Research Unit, Department of Pharmaceutics, Dr. B.C.Roy College of Pharmacy \& AHS, Durgapur-06, West Bengal, India, Tel: +91-943417444; E-mail: santanu_nil@ rediffmail.com, madhusmruti_K@rediffmail.com

Received October 10, 2014; Accepted October 10, 2013; Published October 14, 2013

Citation: Khandai M, Chakraborty S, Ghosh AK (2013) Losartan Potassium Loaded Bioadhesive Micro-Matrix System: An Investigation on Effects of Hydrophilic Polymeric Blend on Drug Release. Pharm Anal Acta S8: 001. doi:10.4172/21532435.S7-001

Copyright: (c) 2013 Khandai M, et al. This is an open-access article distributed under the terms of the Creative Commons Attribution License, which permits unrestricted use, distribution, and reproduction in any medium, provided the original author and source are credited. 
Citation: Khandai M, Chakraborty S, Ghosh AK (2013) Losartan Potassium Loaded Bioadhesive Micro-Matrix System: An Investigation on Effects of Hydrophilic Polymeric Blend on Drug Release. Pharm Anal Acta S8: 001. doi:10.4172/2153-2435.S7-001

Page 2 of 5

gelation in presence of divalent metal ions which upon cross linking give rise to metalo-alginate hydrogels [7]. Guar gum is a natural nonionic polysaccharide obtained from the seeds of Cyamopsis tetragonolobus (Family Leguminosae). Guar gum consists of a linear chain of $\beta$ - $(1 \rightarrow 4)$-linked $D$-mannose units with $\mathrm{D}$-galactose attached by $\alpha-(1 \rightarrow 6)$ linkages to every other mannose unit to form short side chains [8]. In pharmaceuticals, guar gum has been used in oral sustain drug delivery as release modifying agent, binders etc.

So, the aim of the present research work is to develop sustain release bioadhesive micro-matrix system of losartan potassium and investigate the effect of combination of hydrophilic swellable polymers (i.e. sodium alginate and guar gum) on various physicochemical parameters and in vitro drug release.

\section{Materials and Methods}

\section{Materials}

Losartan potassium (LP) was a generous gift sample procured from Alkem Pvt. Ltd., Mumbai, India. Sodium alginate (viscosity $\approx 3500 \mathrm{cps}$ ) was received as a gift from Himedia laboratories, India. Guar gum (viscosity in the range of 3500-4000 cps) was procured from Sigma Chemicals (St. Louis, MO). Calcium chloride was a gift from Loba Chem., Pvt. Ltd., India. All other chemicals and solvents were of analytical grade.

\section{Development of algino-guar micro matrix system}

Algino-guar polymeric micro matrix system of losartan potassium was fabricated by ionic gelation technique [9] (Table 1). The polymeric excipients sodium alginate and guar gum solutions were separately prepared by dissolving both the polymers in sufficient amount of water under gentle agitation. Then the guar gum solution was added slowly to sodium alginate solution and the polymeric blend was stirred properly until a homogenized algino-guar polymeric mixture was obtained. In this polymeric blend, losartan potassium (LP) was added and mixed at $8000 \mathrm{rpm}$ using Ultraturrax (Jahnke and Kunkel, Germany) for 2 min. Then the drug containing algino-guar polymeric dispersion was extruded drop wise employing a $24 \mathrm{G}$ needle to a $5 \%$ calcium chloride solution with continuous stirring at $1000 \mathrm{rpm}$. The entire process was continued for 30 minutes to obtain rigid microparticles. After 30 minutes, the microspheres were collected and washed with distilled water to removed any undissolve drug or excipients or any impurities. Then the microspheres were dried overnight at room temperature. Then the prepared losartan potassium loaded algino-guar polymeric microspheres were kept in desiccator for future use.

\section{Characterisation of losartan potassium loaded microparticles}

Encapsulation efficiency: The encapsulation efficiency of the microspheres was determined based the method reported by Agnihotri et al. [10]. An accurately weighed algino-guar microspheres (100 mg) containing losartan potassium were placed in $100 \mathrm{ml}$ of distilled water and vigorous stirred for 4 hours. The resulting dispersion was sonicated for $30 \mathrm{~min}$. using a sonicator (Imeco Sonifier, Imeco Ultrasonics, India) to extract the total drug present in the microspheres and then filtered out through whatman filter paper $(0.45 \mathrm{~mm})$. Then, the polymeric debris was washed twice with fresh solvent to extract any adhering drug which may remain in the swell polymeric debris. The clear solution (free from any polymeric flakes) was analysed spectrophotometrically at 252 nm (UV-2450, Shimadzu, Japan) to determine amount of losartan potassium present in the microparticles (Table 2). Each determination was made in triplicate and encapsulation efficiency (\%) was calculated as follows,

Entrapment efficiency $(\%)=\frac{\text { total amount of drug in microspheres }}{\text { total amount of drug added initially }} \times 100$

Yield (\%): The percentage yield of algino-guar microspheres was calculated using the weight of dried microspheres with respect to the weight of starting material and percentage yield (Table 2) of each batch was calculated as per the following formula,

$$
\text { Yield }(\%)=\frac{\text { weight of dried microshperes }}{\text { weight of starting material }} \times 100
$$

Granule size analysis: Sieve analysis method was used to determine the granule size of each formulation [11]. The granules of each batch were separated into different size fractions (\% mass fraction) using standard sieves having nominal mesh apertures of 1.4, 1.2, 1.0, 0.85 and $0.71 \mathrm{~mm}$. The granules retained on each sieve were collected separately and weighed. The study was conducted in triplicate and mean granule size of each formulation was calculated using the following formula,

$$
\text { Mean granule size }=\frac{\sum(\text { mean granule size of the fraction } \times \text { weight fraction })}{\sum \text { weight fraction }}
$$

In vitro drug release study: The drug release pattern of losartan potassium from the prepared algino-guar polymeric microspheres was determined using USP six stage dissolution rate test apparatus II (Thermolab; India) at $50 \mathrm{rpm}$. Accurately weighed quantity of microspheres (equivalent to $50 \mathrm{mg}$ of pure losartan potassium) was suspended in the dissolution vessel holding $900 \mathrm{ml}$ of phosphate buffer ( $\mathrm{pH}$ 6.8) [12]. The dissolution medium was stirred at $50 \mathrm{rpm}$ and maintained constant temperature of $37 \pm 0.5^{\circ} \mathrm{C}$ for the entire study duration. At each predetermined time intervals, $5 \mathrm{ml}$ of aliquots were withdrawn from the dissolution vessel and an equal quantity of fresh dissolution media was replaced to dissolution vessel for maintaining the sink condition. Then the samples were suitably diluted and analyzed at $252 \mathrm{~nm}$ for drug content using UV-Visible spectrophotometer (UV2450 Shimadzu, Japan). The release studies were conducted in triplicate and data were shown in Figure 1.

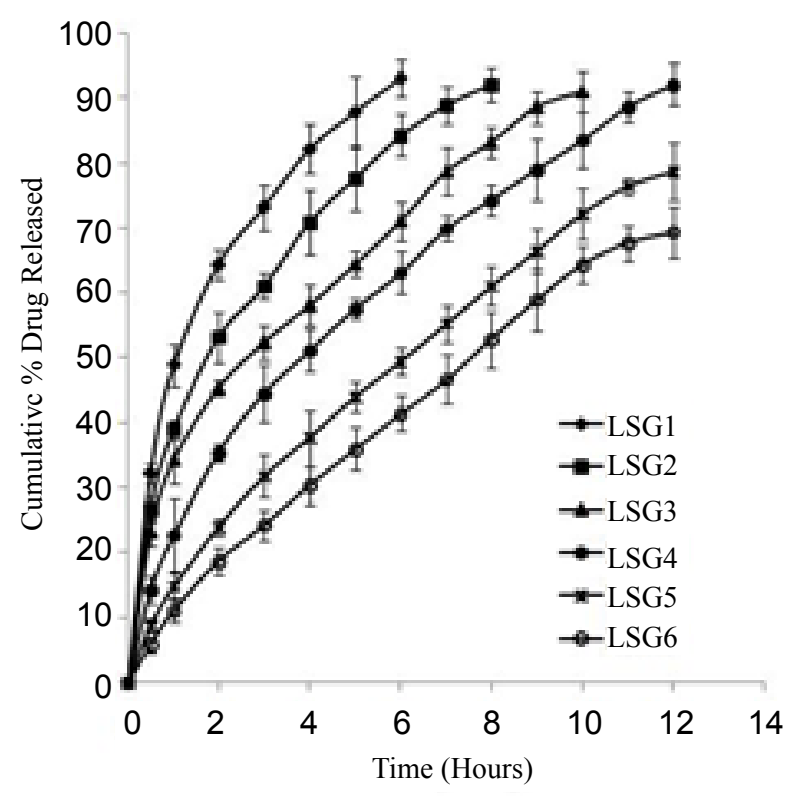

Figure 1: In-vitro dissolution profile of algino-guar microspheres demonstrating the influence of polymeric concentrations (mean $\pm S D, n=3$ ). 
Citation: Khandai M, Chakraborty S, Ghosh AK (2013) Losartan Potassium Loaded Bioadhesive Micro-Matrix System: An Investigation on Effects of Hydrophilic Polymeric Blend on Drug Release. Pharm Anal Acta S8: 001. doi:10.4172/2153-2435.S7-001

Page 3 of 5

\begin{tabular}{|c|c|c|c|c|c|}
\hline Formulation Code & Polymers blend (\% w/w) & Drug level (g) & Cross-linking agent/level (\% w/v) & Curing time (min) & Stirring Speed (rpm) \\
\hline $\mathrm{F} 1$ & Sodium alginate, $1 \%$ + Guar Gum, $1 \%$ & 1 & $\mathrm{CaCl}_{2}, 5 \%$ & 30 & 1000 \\
\hline $\mathrm{F} 2$ & Sodium alginate, $1 \%+$ Guar Gum, $2 \%$ & 1 & $\mathrm{CaCl}_{2}, 5 \%$ & 30 & 1000 \\
\hline F3 & Sodium alginate, $1 \%+$ Guar Gum, $3 \%$ & 1 & $\mathrm{CaCl}_{2}, 5 \%$ & 30 & 1000 \\
\hline $\mathrm{F} 4$ & Sodium alginate, $1 \%$ + Guar Gum, $4 \%$ & 1 & $\mathrm{CaCl}_{2}, 5 \%$ & 30 & 1000 \\
\hline F5 & Sodium alginate, $1 \%$ + Guar Gum, $5 \%$ & 1 & $\mathrm{CaCl}_{2}, 5 \%$ & 30 & 1000 \\
\hline F6 & Sodium alginate, $1 \%+$ Guar Gum, $6 \%$ & 1 & $\mathrm{CaCl}_{2}, 5 \%$ & 30 & 1000 \\
\hline
\end{tabular}

Table 1: Composition of losartan potassium loaded of algino-guar micro matrix system.

\begin{tabular}{|c|c|c|}
\hline Formulation Code & \% Yield & Encapsulation efficiency $(\%)$ \\
\hline F1 & $86.23 \pm 3.47$ & $64.48 \pm 2.87$ \\
\hline F2 & $87.77 \pm 3.92$ & $69.96 \pm 3.04$ \\
\hline F3 & $89.08 \pm 2.90$ & $74.39 \pm 2.18$ \\
\hline F4 & $95.29 \pm 2.88$ & $82.22 \pm 3.87$ \\
\hline F5 & $91.18 \pm 4.33$ & $85.12 \pm 2.28$ \\
\hline F6 & $80.69 \pm 3.29$ & $87.78 \pm 3.29$ \\
\hline
\end{tabular}

Table 2: Characterization of algino-guar micro matrix system.

Analysis of release profiles: To investigate the mechanism of drug-release and to compare the performance of various matrix formulations, the percentage drug-release versus time profile were used. The goodness of fit was performed using kinetics models such as zero-order, first order, Higuchi and Peppas model (Table 3).

Higuchi's square root model [13] primarily describes drug release from a heterogeneous matrix by diffusion through the intergranular openings created by the porosity of the matrix. This model can be used to describe the drug diffusion from different types of modified release pharmaceutical dosage forms including microsphere system.

$$
Q=k_{H} t^{1 / 2}
$$

where $Q$ is the percentage of drug released in time $t, \mathrm{k}_{\mathrm{H}}$ is the Higuchi release rate.

Peppas equation $[14,15]$,

$$
M_{t} / M_{\infty}=k t^{n}
$$

Where $\mathrm{n}=$ release exponent indicative of the mechanism of drug release, $M_{t} / M_{\infty}$ is the fractional release of the drug, $t$ is the release time, $\mathrm{K}$ is the kinetic rate constant. Thus $\mathrm{M}_{\mathrm{t}} / \mathrm{M} \infty$ is the fraction of drug release at time $t$, a measure of the primary mechanism of the drug release and $\mathrm{n}$ characterizes the mechanism of drug release from the formulations during dissolution process.

Statistical analysis: In vitro drug release data of all the formulations were subjected to one way analysis of variance (one way ANOVA) followed by Holm-Sidak multiple comparison analysis to find out any significant difference. Statistical analysis of the data was performed at a confidence limit of $\mathrm{P}<0.05$ using the software PRISM (Graph pad, San Diego, CA, USA).

Bio-adhesive property of microspheres: The bio-adhesive property of the prepared algino-guar microspheres was evaluated employing the method described by Lehr et al. [16]. The test was performed at both simulated gastric fluid $(0.1 \mathrm{~N} \mathrm{HCl}, \mathrm{pH} 1.2)$ and simulated intestinal fluid (phosphate buffer, $\mathrm{pH}$ 6.8) (Figure 2). The fresh excised pieces of goat intestinal mucosa were collected approximately having dimension of $2 \times 3 \mathrm{~cm}$ and clipped on to a glass slide using cyanoacrylate glue. About 50 nos. of microspheres were spread onto each wet rinsed tissue specimen and immediately thereafter the slides with suitable support were hung onto the arm of a USP tablet disintegrating test machine.
Then the entire tissue sample was given a steady and slow up and down movement within the test fluid at $37^{\circ} \mathrm{C}$. At regular time intervals, the number of microspheres still adhering to the tissue was counted. Each determination was made in triplicate and the adhering percent was calculated by the following formula,

$$
\text { Adhesion }(\%)=\frac{\text { number of microspheres adhered }}{\text { number of microspheres applied }} \times 100
$$

Scanning electron microscopic (SEM) studies: The surface morphology of the optimized formulation was examined using a Scanning Electron Microscope (S-530, HITACHI, Japan). The samples were placed on an aluminium stub and mounted using adhesive tape. Then the stub was coated with conductive gold with sputter coater attached to the instrument and placed in the scanning electron microscope chamber at acceleration voltage of $20 \mathrm{kV}$ and chamber pressure of $0.6 \mathrm{~mm} \mathrm{Hg}$. The photograph was taken using scanning electron microscope (Figure 3).

\section{Drug excipients compatibility studies \\ FTIR studies}

FTIR spectra of pure drug (PD) and optimized microsphere formulation (OF) were obtained using FTIR analyzer (Prestige-21, Shimadzu FT-IR, Japan) to study the possible interactions between the pure drug and polymers (Figure 4). The samples were prepared on $\mathrm{KBr}$-press (Kimaya Engineers, India) under hydraulic pressure of 5 Ton and scanned over the range of $4000-400 \mathrm{~cm}^{-1}$.

\section{Thermal property studies}

Thermal property study was conducted using Differential Scanning Calorimetric analysis to study whether any interactions were present among the drug and polymers or not. DSC thermogram of pure drug (PD) and optimized formulation (OF) were obtained (Figure 5) using a Differential Scanning Calorimeter (Diamond DSC, PYRIS, Perkin Elmer, USA). Indium standard was used to calibrate the DSC temperature and enthalpy scale. The samples were sealed in perforated aluminum pans and heated at a constant rate of $10^{\circ} \mathrm{C} / \mathrm{min}$ over a temperature range of $50^{\circ} \mathrm{C}$ to $400^{\circ} \mathrm{C}$.

\section{$\mathrm{X}$-ray diffraction (XRD) studies}

Samples of pure losartan potassium (PD) and drug loaded optimized 


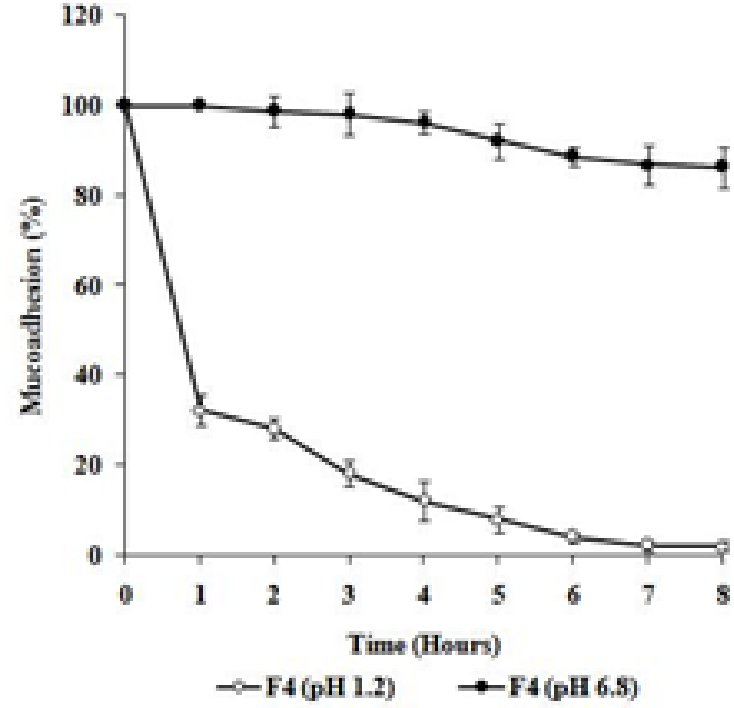

Figure 2: Bioadhesion behavior of algino-guar optimized formulation (F4) in $0.1 \mathrm{~N} \mathrm{HCl}(\mathrm{pH} \mathrm{1.2)}$ and in phosphate buffer $(\mathrm{pH} 6.8)$ medium (mean $\pm \mathrm{SD}, \mathrm{n}$ $=3$ ).

formulation (OF) were assessed for crystallinity by X-ray diffractometer (X'Pert Pro, Panalytical, Nertherlands) using monochromatized $\mathrm{Cu} \mathrm{K}$ $\alpha-1$ radiation $(\lambda=1.54 \AA)$. The voltage and current were $45 \mathrm{kV}$ and 40 $\mathrm{mA}$, respectively. Measurements were carried out in the angular scan range from $5^{\circ}$ to $40^{\circ}(2 \theta)$ at a scan speed of $1^{\circ} / \mathrm{min}$. The XRD spectra of all the samples are shown in Figure 6.

\section{Stability studies}

Optimized microsphere formulation containing losartan potassium was subjected to six months stability studies at laboratory ambient conditions $\left(25 \pm 2{ }^{\circ} \mathrm{C}\right.$ and $\left.60 \pm 5 \% \mathrm{RH}\right)$. After each 30 days interval, $\%$ drug content, shelf life and physical appearance of the optimized microsphere was evaluated (Table 4).

\section{Results and Discussion}

Algino-guar based losartan potassium loaded micro matrix system was fabricated by ionic gelation method (Table 1). This technique was selected due to its simple processing, cost effectiveness and non utility of organic solvents.

\section{Characterisation of losartan potassium loaded microparticles}

Granule size analysis and encapsulation efficiency: The granule size of the prepared algino-guar microsphere formulations was found from $679.63 \pm 6.69 \mu \mathrm{m}$ to $937.92 \pm 10.76 \mu \mathrm{m}$ while the encapsulation efficiency was found to be $64.48 \pm 2.87 \%$ to $87.78 \pm 3.29 \%$ (Table 2). From the experiment it was observed that as there was increase in the amount of polymer, the granules depicted observable increase in size and encapsulation efficiency. This may be justified by the fact that low polymeric concentration produce less viscous inner phase which was not be able to produce the rigid coacervate. As a result the coacervate may get broken off [17] and smaller granules were formed.

But when the polymer concentration increases, the viscosity of the inner phase and rigidity of the coacervate were also increased which may increase the size of the granules. Again at higher polymeric concentration, the viscosity of the medium and availability of calcium binding sites in the polymeric chains get increases. As a result the degree of cross-linking is enhanced and larger granules are formed which entrapped greater amount of drug [18].

Yield: The \% yield of all the formulations was found within the range of $80.69 \pm 3.29 \%$ to $95.29 \pm 2.88 \%$ (Table 2). It was observed that there was profound improvement in the \% yield value as the polymer concentration increased. This may be due to the fact that by increasing the weight of polymers in a fixed volume of solvent resulted in an increase in particle size which led to an increase in the \% yield of the formulations. For formulation F6, the \% yield was less (as compared with F4 and F5) which may be due to the loss of microspheres during the washing and recovering process.

In vitro drug release study: In vitro drug dissolution study has been performed by using phosphate buffer ( $\mathrm{pH}$ 6.8) rather than distilled water. As per Bonfilio et al. [19], the use of water as a dissolution medium is discouraged because test condition such as $\mathrm{pH}$ and surface tension can vary depending on water source and may change during the dissolution test itself. So in this research the author have selected phosphate buffer ( $\mathrm{pH}$ 6.8) as dissolution media.

The drug release pattern from the prepared microspheres is shown in Figure 1. Formulation F1, F2, and F3 could sustain the drug release for 6,8 and 10 hours respectively. Formulation F1 was able to release $93.17 \pm 2.78 \%$ drug at 6 hours, F2 was able to release $92.18 \pm 2.70 \%$ drug at 8 hours and F3 was able to release $91.14 \pm 3.21 \%$ drug at 10 hours. Formulation F4 (sodium alginate : guar gum; 1:4) was able to sustain the drug release upto 12 hours and $92.18 \pm 3.24 \%$ drug was release within 12 hours. Further increasing the concentration of guar gum i.e. in formulation F5 and F6, the drug release was too retarded and only $78.79 \pm 4.39 \%$ and $69.46 \pm 3.91 \%$ drug was release at 12 hours.

From the dissolution study it is clear that polymer concentration plays a major role in drug release from the algino-guar microspheres i.e. at low polymeric concentration drug release rate was faster and slow at high polymeric concentration. This may be due to the fact that at low polymeric concentration, matrix density and porosity get reduce which allows more solvent to penetrate in the microsphere system and increase the drug release rate. But at higher polymeric concentration, a thick swelled polymeric gel layer was formed around the microsphere which decreases the rate of drug release. Higher polymeric concentration may also increases the diffusional path length around the matrix which might be acting as a contributing factor to retard the drug diffusion from the prepared algino-guar microspheric formulations.

For formulations F1 and F2 (sodium alginate : guar gum; 1:1 and 1:2 respectively), little bit high amount of drug was diffused at initial stage of dissolution. This may be due to the fact that these formulations underwent erosion before complete swelling could take place and release high amount of drug.

It was also observed from the study that the release behavior of losartan largely depend on the concentration of guar gum. When the concentration of guar gum was increase, drug release rate was decreased. This may be due to the fact that hydration of individual guar gum particles results in extensive swelling which maintained the integrity of the microspheric system, retard further penetration of the dissolution medium and prolonged the drug release [20,21].

In vitro drug release data were subjected to various kinetics models. Kinetics analysis shows that all the formulations were best characterized by Korsmeyer-Peppas model. From the release exponent 
Citation: Khandai M, Chakraborty S, Ghosh AK (2013) Losartan Potassium Loaded Bioadhesive Micro-Matrix System: An Investigation on Effects of Hydrophilic Polymeric Blend on Drug Release. Pharm Anal Acta S8: 001. doi:10.4172/2153-2435.S7-001

Page 5 of 5

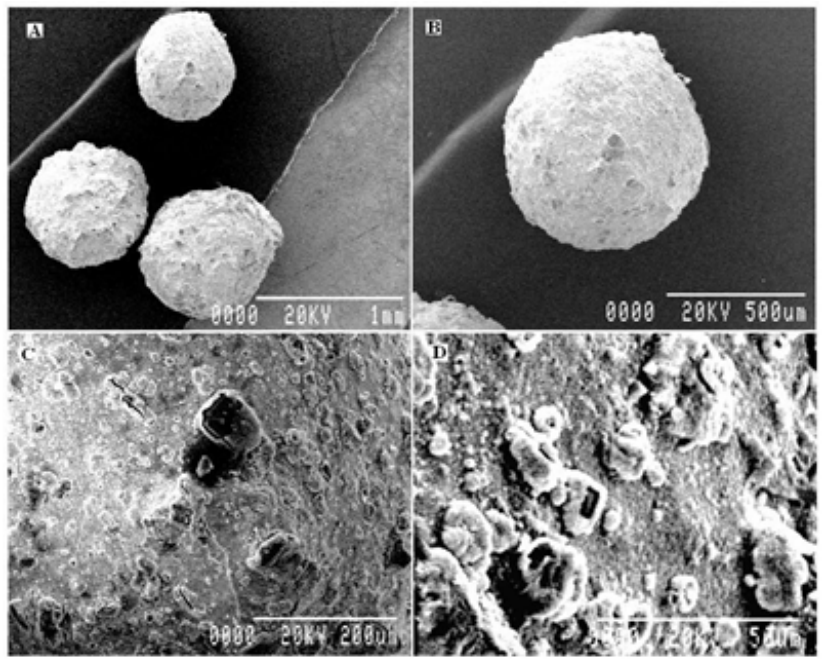

Figure 3: Scanning electron micrographs of optimized microsphere formulation ( $F 4)(A=30 X, B=60 \times, C=200 X, D=1000 X)$.

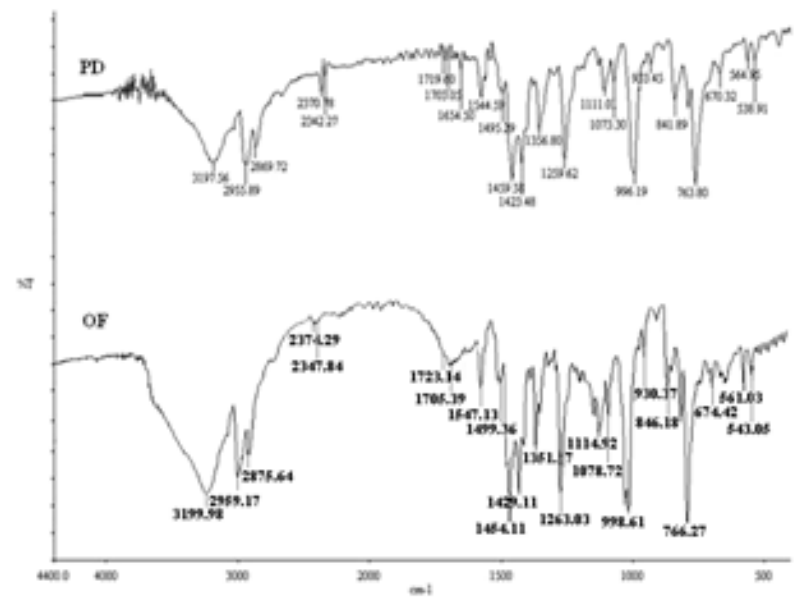

Figure 4: FTIR spectra of losartan potassium (PD) and optimized microsphere formulation (OF) containing drug and polymers.

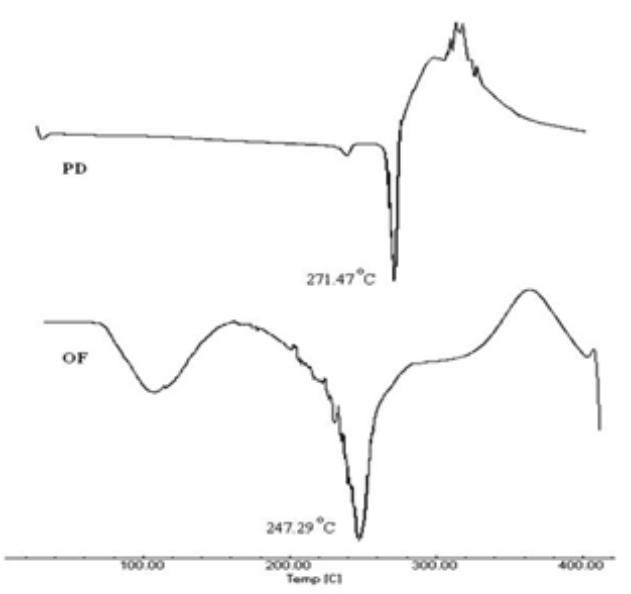

Figure 5: DSC thermogram of losartan potassium (PD) and optimized microsphere formulation

(OF).

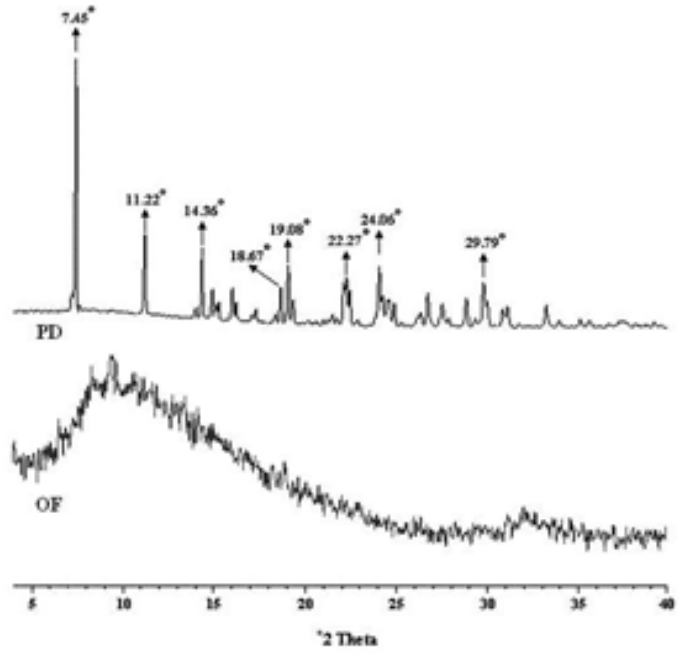

Figure 6: X-Ray diffraction pattern of losartan potassium (PD) and optimized microsphere formulation (OF) containing drug and polymers.

in the Korsmeyer-Peppas model, it can be suggested the mechanism that led to the release of losartan potassium was Fickian diffusion mechanism ( $\mathrm{n}=0.414$ to 0.446 ) (Table 3 ). So it is concluded that a combined release mechanism of drug diffusion and spheres erosion might be appropriate for the release of losartan potassium from the prepared algino-guar micro matrix system.

One way analysis of variance suggested a significant difference in drug release at $\mathrm{p}<0.05$ among all the formulations. Holm-Sidak multiple comparison analysis also suggested a significant difference among all the formulations with respect to in vitro drug release.

From the in vitro drug release study it was cleared that among all the algino-guar formulations, F4 shows the best dissolution profile (i.e. more than $90 \%$ drug was released up to 12 hours). So, F4 formulation was selected as an optimized formulation for further studies.

\section{Bioadhesive property of optimized microspheres}

The optimized microsphere formulation (F4) exhibited good bioadhesion properties as observed in in-vitro wash-off test. It was observed that algino-guar microspheres have less bioadhesion property in simulated gastric fluid $(\mathrm{pH}$ 1.2) as compared with simulated intestinal fluid ( $\mathrm{pH}$ 6.8). It was observed that formulation F4 exhibited $86.24 \pm 4.68 \%$ mucoadhesion up to 8 hours in $\mathrm{pH} 6.8$ buffer solution whereas $2.10 \pm 1.12 \%$ mucoadhesion was observed up to 8 hours in $\mathrm{pH} 1.2$ buffer solution (Figure 2). This may be due to the fact that sodium alginate is practically insoluble in aqueous acidic solution i.e. simulated gastric fluid whereas in simulated intestinal fluid, the carboxyl acid group and other functional groups present in sodium alginate get ionized which helps to increase its solubility and hydration property. The increase in solubility and hydration allows more solvent to penetrate the polymeric coat, produce a viscous gel and increase the bioadhesion property [9,22]. Similarly, guar gum also plays an important role in bioadhesion mechanism. In presence of high concentration of $\mathrm{H}^{+}$ion, there is reduction in protonation of $\mathrm{OH}^{-}$ion of galactomannan unit of guar gum which may lower the inter and intra molecular hydrogen bonding. These two synergistically contribute to decrease the adhesive strength at lower $\mathrm{pH}$ while revert back at higher $\mathrm{pH}$ and increase the bioadhesion of the formulation to the intestinal tissue. Therefore, it is concluded from the in vitro wash-off test that 
Citation: Khandai M, Chakraborty S, Ghosh AK (2013) Losartan Potassium Loaded Bioadhesive Micro-Matrix System: An Investigation on Effects of Hydrophilic Polymeric Blend on Drug Release. Pharm Anal Acta S8: 001. doi:10.4172/2153-2435.S7-001

Page 6 of 5

\begin{tabular}{|c|c|c|c|c|c|}
\hline \multirow{3}{*}{$\begin{array}{c}\begin{array}{c}\text { Models } \\
\text { Formulation }\end{array} \\
\text { F1 }\end{array}$} & \multirow{3}{*}{$\begin{array}{c}\frac{\text { Zero order }}{R^{2}} \\
0.839\end{array}$} & \multirow{3}{*}{$\begin{array}{c}\frac{\text { First order }}{R^{2}} \\
0.989\end{array}$} & \multirow{3}{*}{$\begin{array}{c}\frac{\text { Higuchi }}{R^{2}} \\
0.982\end{array}$} & \multicolumn{2}{|c|}{ Korsmeyer-Peppas } \\
\hline & & & & $R^{2}$ & $n$ \\
\hline & & & & 0.991 & 0.414 \\
\hline $\mathrm{F} 2$ & 0.881 & 0.992 & 0.993 & 0.996 & 0.442 \\
\hline F3 & 0.912 & 0.980 & 0.991 & 0.995 & 0.445 \\
\hline F4 & 0.943 & 0.975 & 0.993 & 0.997 & 0.436 \\
\hline F5 & 0.977 & 0.992 & 0.985 & 0.999 & 0.419 \\
\hline F6 & 0.988 & 0.992 & 0.970 & 0.998 & 0.446 \\
\hline
\end{tabular}

Table 3: In vitro kinetic model fitting.

\begin{tabular}{|c|c|c|c|c|}
\hline Condition & $\begin{array}{c}\text { Sampling Interval } \\
\text { (days) }\end{array}$ & $\begin{array}{c}\text { Drug Content } \\
(\%)\end{array}$ & $\begin{array}{c}\text { Physical } \\
\text { appearance }\end{array}$ & $\mathrm{t}_{90 \%}$ (years) \\
\hline \multirow{3}{*}{$25{ }^{\circ} \mathrm{C} / 60 \% \mathrm{RH}$} & 30 & $99.71(1.09)$ & + & \multirow{2}{*}{2.56} \\
\cline { 2 - 4 } & 60 & $99.25(1.15)$ & + \\
\cline { 2 - 4 } & 90 & $98.98(2.57)$ & + \\
\cline { 2 - 4 } & 120 & $98.59(3.01)$ & + \\
\cline { 2 - 4 } & 150 & $98.27(1.70)$ & + \\
\cline { 2 - 4 } & 180 & $98.06(1.98)$ & + \\
\end{tabular}

Table 4: Stability study of optimized microsphere (F4) at laboratory ambient conditions.

algino-guar microspheres were adhere to the intestine mucosa for a prolonged period and release the drug in a sustained manner before being eroded off.

\section{Surface structure observation}

The surface morphology and shape of the optimized microspheres (F4) were analysed by scanning electron microscopy (Figure 3). It was found from the study that prepared microspheres were almost spherical in shape with rough surface texture.

\section{Drug excipient compactibility studies}

\section{FTIR interpretation}

The IR spectra of the pure drug (PD) and the optimized alginoguar formulation (F4) was scanned over a wave number range of 4400$400 \mathrm{~cm}^{-1}$ in FTIR (Prestige-21, Shimadzu FT-IR, Japan) (Figure 4). The FTIR spectral interpretation from the FTIR spectra revealed that pure losartan potassium exhibited peaks at 3197.56 which represent the presence of $\mathrm{NH}$ stretching, 2955.89 for stretching vibration of $\mathrm{CH}$ of aromatic hydrocarbon chromophore, 1544.59 for C-C multiple bond stretching, 1459.58 and 1423.48 represent $\mathrm{CH}$ bending of $\mathrm{CH}$ group of $\mathrm{CH}_{3}, 1259.62$ for stretching vibration of $\mathrm{C}-\mathrm{N}, 841.89$ for adjutants $\mathrm{H}$ atom in aromatic ring and 763.80 for stretching vibration due to presence of C-Cl. It was observed from the FTIR study that all the major shoulders of losartan potassium were almost intact in the optimized microspheres formulation (F4) which leads to the conclusion that there is no significant redistribution of electronic density in the structure of pure drug when it was incorporated in the microsphere formulation.

\section{Thermal property studies}

The DSC thermographs of pure losartan potassium (PD) and drug loaded algino-guar microspheres (OF) are shown in Figure 5. It was observed that pure losartan potassium showed sharp melting endotherm at $271.47^{\circ} \mathrm{C}$ corresponding to its melting point. But in the optimized formulation (OF), the intensity and sharpness of the endothermic peak of losartan potassium was significantly decreased and the endothermic peak of losartan potassium was found at $247.29^{\circ} \mathrm{C}$. This observation revealed partial dissolution of losartan potassium in the algino-guar polymeric matrix and concluded that pure losartan

potassium changes its state from crystalline to amorphous, dissolved or molecularly dispersed state in the optimized formulation.

\section{$\mathrm{X}$-ray diffraction (XRD) studies}

X-ray diffraction studies were undertaken to confirm the physicochemical state of losartan potassium in the optimized microsphere formulation (Figure 6). The XRD spectra of pure losartan potassium (PD) depicted distinctive peaks at $2 \theta$ values of $7.45^{\circ}, 11.22^{\circ}$, $14.36^{\circ}, 18.67^{\circ}, 19.08^{\circ}, 22.27^{\circ}, 24.06^{\circ}, 29.79^{\circ}$ etc., indicating the presence of crystalline losartan potassium. But in the optimized microsphere formulation (OF), no crystalline peaks of losartan potassium were observed. This result presumed that the drug molecule was dispersed at the molecular level and the crystallinity of the drug was not shown by X-ray diffraction study. So it is concluded that losartan potassium is present as an amorphous form in the algino-guar microsphere formulation.

\section{Stability studies}

Optimized microsphere formulation was subjected to stability studies at laboratory ambient conditions $\left(25 \pm 2{ }^{\circ} \mathrm{C}\right.$ and $60 \pm 5 \%$ $\mathrm{RH})$ and \% drug content, shelf life and physical appearance of the microsphere was evaluated (Table 4). It was observed that no significant changes occurred in the physical appearance and \% drug content of the optimized formulation was found to be $98.06 \pm 1.98 \%$ after 180 days at laboratory ambient conditions. The shelf life of the prepared algino-guar formulation was found to be 2.56 years. So, the stability study revealed the stable nature of losartan potassium loaded alginoguar microspheres.

\section{Conclusion}

Effects of combination of hydrophilic swellable polymeric blend on drug release and on bioadhesion of the prepared algino-guar microspheres were studies. The results of the experiments concluded that algino-guar polymeric blend exhibit promising bioadhesion properties as well as sustained release of losartan potassium. Theoretical models of drug release indicated that drug release from the microspheres was triggered by diffusion and spheres erosion of the polymer chain. So the present study concluded that algino-guar polymeric microspheres may be used as the best tool to deliver losartan potassium in a sustained manner as twice daily sustain release dosage form.

\section{References}

1. Madgulkar A, Bhalekar M, Swami M (2009) In vitro and In vivo studies on chitosan beads of losartan duolite AP143 complex, optimized by using statistical experimental design. AAPS Pharm Sci Tech 10: 743-751.

2. Johnston $\mathrm{Cl}$ (1995) Angiotensin receptor antagonists: focus on losartan Lancet 346: 1403-1407.

3. Ferrero C, Muñoz-Ruiz A, Jiménez-Castellanos MR (2000) Fronts movement as a useful tool for hydrophilic matrix release mechanism elucidation. Int $\mathrm{J}$ Pharm 202: 21-28.

4. Khandai M, Chakraborty S, Ghosh AK (2014) Critical analysis of algino-carbopol multiparticulate system for the improvement of flowability, compressibility and tableting properties of a poor flow drug. Powder Technol 253: 223-229.

5. Baveja SK, Rao RKV, Devi PK (1987) Zero-order release hydrophilic matrix tablets of $\beta$-adrenergic blockers. Int J Pharm 39: 39-45.

6. Khandai M, Chakraborty S, Pathak A, Ghosh AK (2013) Algino-losartan mucoadhesive microspheres: an unique device for prolonged drug delivery. Int J Pharm Sci Rev Res 18: 97-103.

7. Smidsrød O, Skjåk-Braek G (1990) Alginate as immobilization matrix for cells Trends Biotechnol 8: 71-78. 
Citation: Khandai M, Chakraborty S, Ghosh AK (2013) Losartan Potassium Loaded Bioadhesive Micro-Matrix System: An Investigation on Effects of Hydrophilic Polymeric Blend on Drug Release. Pharm Anal Acta S8: 001. doi:10.4172/2153-2435.S7-001

8. Krishnaiah YSR, Al-Saidan SM, Patro SS, Satyanaryana V (2005) In vitro and in vivo evaluation of guar gum matrix tablets for oral controlled release of watersoluble diltiazem hydrochloride. AAPS Pharm Sci Tech 6: E14-21.

9. Chakraborty S, Khandai M, Sharma A, Khanam N, Patra CN, et al. (2010) Preparation, in vitro and in vivo evaluation of algino-pectinate bioadhesive microspheres: An investigation of the effects of polymers using multiple comparison analysis. Acta Pharm 60: 255-266.

10. Agnihotri SA, Jawalkar SS, Aminabhavi TM (2006) Controlled release of cephalexin through gellan gum beads: effect of formulation parameters on entrapment efficiency, size, and drug release. Eur J Pharm Biopharm 63: 249261.

11. Viswanathan NB, Thomas PA, Pandit JK, Kulkarni MG, Mashelkar RA (1999) Preparation of non-porous microspheres with high entrapment efficiency of proteins by a (water-in-oil)-in-oil emulsion technique. J Control Release 58: 9-20.

12. Hossain MS, Sarwar SM (2012) Development and evaluation of sustained release losartan potassium matrix tablet using kollidon SR as release retardant. Brazilian J Pharm Sci 48: 621-628.

13. Higuchi T (1963) Mechanism Of Sustained-Action Medication. Theoretical Analysis Of Rate Of Release Of Solid Drugs Dispersed In Solid Matrices. J Pharm Sci 52: 1145-1149.

14. Ritger PL, Peppas NA (1987) A simple equation for description of solute release II. Fickian and anomalous release from swellable devices. J Control Rel 5: 37-42.
15. Korsmeyer RW, Gurny R, Docler E, Buri P, Peppas NA (1983) Mechanism of solute release from porous hydrophilic polymers. Int J Pharm 15: 25-35.

16. Lehr CM, Bowstra JA, Tukker JJ, Junginger HE (1990) Intestinal transit of bioadhesive microspheres in an in situ loop in the rat-A comparative study with copolymers and blends based on poly (acrylic acid). J Control Rel 13: 51-62.

17. Jha AK, Bhattacharya A (2008) Preparation and in vitro evaluation of sweet potato starch blended sodium alginate microbeads. Adv Nat Appl Sci 2: 122 128.

18. El-Kamel AH, Al-Gohary OM, Hosny EA (2003) Alginate-diltiazem hydrochloride beads: optimization of formulation factors, in vitro and in vivo availability. J Microencapsul 20: 211-225.

19. Bonfilio R, Mendonca TF, Pereira GR, Araujo MB, Tarley CRT (2010) Losartan potassium dissolution test for drug release evaluation in pharmaceutical capsules using HPLC and UV spectrophotometry. Quím Nova 33: 377-383.

20. Yadav AS, Rao V, Rao SB, Kulkarni SV (2010) Design and evaluation of gua gum based controlled release matrix tablets of zidovudine. J Pharm Sci Tech 2: $156-162$

21. Casas JA, Mohedano AF, Garcia-Ochoa F (2000) Viscosity of guar gum and xanthan/guar gum mixture solutions. J Sci Food Agric 80: 1722-1727.

22. Yang J, Chen SH, Fang Y (2009) Viscosity study of interactions between sodium alginate and $\mathrm{CTAB}$ in dilute solutions at different $\mathrm{pH}$ value. Carbohydrate Polymers 75: 333-337. 